\title{
Giardiosis and other enteropathogenic infections: a study on diarrhoeic calves in Southern Germany
}

\author{
Julia Gillhuber ${ }^{1 *}$, David Rügamer ${ }^{2}$, Kurt Pfister $^{1}$ and Miriam C Scheuerle ${ }^{1}$
}

\begin{abstract}
Background: Diarrhoea induces massive problems in the rearing of calves. The aim of the study was to obtain current data about the frequency of Giardia spp., Cryptosporidium spp. and Eimeria spp. in diarrhoeic calves in Southern Germany with the particular focus on giardiosis.

Results: 1564 samples were analysed for the three pathogens using microscopical methods. Giardia spp. was detectable in 112/1564 samples (7.2\%). The mean age was 46.5 days and the odds of being infected with Giardia spp. increased slowly up to 8 times from about 12 days to 30 days of age. There appeared to be no seasonal influence on the frequency of Giardia spp. A mono-infection with Giardia spp. was diagnosed in 46 calves (2.9\%) whereas 15 calves (1.0\%) had a mixed-infection with Cryptosporidium spp. and 51 calves (3.3\%) with Eimeria spp. Cryptosporidium spp. and Eimeria spp. could be detected in 646/1564 samples (41.3\%) and 208/1564 samples (13.3\%), respectively, with a mean age of 11.3 and 55.0 days, respectively. The odds of being infected with Cryptosporidium spp. increased up to 4.5 times until an age of 10 days. After that the odds decreased continuously and was approaching zero at about 30 days. The odds of being infected with Eimeria spp. increased continuously up to 30 times from about 20 days to 60 days of age. There appeared to be no significant seasonal influence on the frequency of Cryptosporidium spp.; but there was one for Eimeria spp.: the odds of being infected with Eimeria spp. in March and April decreased by about half and increased up to 2.3 times between July and September.

Additionally, as requested by the veterinarians, 1282 of those samples were analysed for E. coli, Rota-, Coronavirus and Cryptosporidium spp. using an ELISA. Obtained frequencies for these pathogens were $0.9 \%, 37.8 \%, 3.4 \%$ and $45.3 \%$ with a mean age of 24.8 days, 12.1 days, 9.0 days and 12.1 days, respectively.

Conclusions: The results indicate that in Southern Germany in addition to Eimeria spp., Giardia spp. seems to play a contributing role in diarrhoea in older calves, whereas Cryptosporidium spp. and Rotavirus are mostly relevant in young calves.
\end{abstract}

Keywords: Giardia, Cryptosporidium, Eimeria, E. coli, Rotavirus, Coronaviurs, Calf, Diarrhoea, Epidemiology, Prevalence

\section{Background}

Diarrhoea induces massive problems in the rearing of calves and is often caused by viral, bacterial and parasitic pathogens.

Giardia spp., Cryptosporidium spp. and Eimeria spp. are the most important protozoan parasites causing gastrointestinal problems including diarrhoea in calves.

Giardia spp. is commonly found in cattle [1] and although this infection is often subclinical or even asymptomatic, it

\footnotetext{
* Correspondence: julia.gillhuber@tropa.vetmed.uni-muenchen.de ${ }^{1}$ Comparative Tropical Medicine and Parasitology, Faculty of Veterinary Medicine, Ludwig-Maximilians-Universität München, Leopoldstr. 5, D-80802 Munich, Germany

Full list of author information is available at the end of the article
}

should be considered as a differential diagnosis in younger calves with acute or chronic diarrhoea, reduced weight gain and ill thrift [1,2]. In this article the taxonomy according to Monis et al. [3] is used. In order to eliminate a taxonomic uncertainty it classifies the Assemblages A-G of the Giardia duodenalis morphological group, the causative agents of giardiosis in humans and mammals, as separate species. According to this, there are eleven species within the genus Giardia, which can either be distinguished morphologically or genetically. Three of them, the zoonotic species G. duodenalis (Assemblages A) and G. enterica (Assemblage B) and the livestock-specific species G. bovis (Assemblage E) can infect cattle. They are morphologically indistinguishable. G. duodenalis and G. enterica are also able 
to infect humans [4] and are therefore of public health significance [5].

Cryptosporidiosis, one of the most important aetiologies of acute diarrhoea, especially in young calves [6], is caused by the intracellular protozoan parasite Cryptosporidium spp. Symptoms of this infection can include dehydration, fever, anorexia, weight loss, weakness and progressive loss of condition [7]. Many of the different species and genotypes of the genus Cryptosporidium, partly with zoonotic potential, are morphologically indistinguishable [8-10]. One of them is C. parvum, a zoonotic genotype often found in young calves and also able to infect humans, hence making the former a source of infection for humans and Cryptosporidiosis a public health issue $[2,11]$. C. bovis, which has the same morphology as C. parvum, and C. andersoni and C. ryanae, which are of another morphological appearance $[8,12]$ are also common causes of infections in cattle [13] but generally they are found in older calves [14-16].

In contrast to these two protozoans with zoonotic potential, Eimeria spp. are strictly host specific $[17,18]$. E. bovis and E. zuernii, commonly found in calves, are highly pathogenic and often associated with diarrhoea with faeces containing blood, fibrin and intestinal tissue $[17,19]$.

Several studies investigating the impact of the season on a protozoan's prevalence, had contrasting results with some finding an influence and others not $[17,20,21]$.

Escherichia coli F5, Rotavirus and Coronavirus are other important enteropathogens associated with diarrhoea in calves. These three together with Cryptosporidium spp. are known to occur in the majority of intestinal infections in calves younger than one month [22].

Differentiation between these viral, bacterial and parasitic agents is only possible by a diagnostic test but not by clinical examination [23]. Since testing under field conditions is not always possible in cases of calf diarrhoea for financial and logistic reasons, it is important for practitioners to know the frequency of the various pathogens in a certain area, the more so as there are no recent data available for Southern Germany.

It is important to emphasize, that management, geographical and climatological parameters and differences in study design, such as the number and age of animals included in the study and the used detection methods can influence the obtained prevalences of pathogens, e.g. Giardia spp. [1]. For Cryptosporidium spp. it has been shown in a study conducted over 6 years that the prevalences varied markedly between the different years and seasons, although the study design did not change [24]. So when studies differ in one or more of the factors mentioned, the results may vary accordingly.

Thus, the aim of the study was to update the current knowledge of enteropathogenic protozoa in Southern
Germany with the focus on the role of Giardia spp. as a cause of diarrhoea in calves compared to the other neonatal and post-neonatal pathogens.

\section{Methods \\ Sample collection}

Large animal veterinarians in Southern Germany were asked to collect faecal samples from ill patients (diarrhoeic calves; age: < one year) and to send them to our laboratory together with a completed questionnaire. All samples were immediately processed after arrival in the laboratory. Subsequently, the results were sent to the veterinarians and the animals were treated if necessary. Thus, an ethical approval was not necessary, as the samples were gained from patients in order to make a diagnosis.

\section{Sample analysis}

All samples were analysed for Giardia spp., Cryptosporidium spp. and Eimeria spp. using microscopic methods at 200-400x magnifications.

For the detection of Cryptosporidium spp. a direct faecal smear of each sample was carbolfuchsin-stained [25], which also allowed to detect Eimeria-oocysts. A Giardia-infection was diagnosed by using merthiolate iodine formaldehyde concentration (MIFC) method with the addition of Lugol's solution [26]. Using the MIFC-method also Cryptosporidium- and Eimeria-oocysts were detectable.

On request of the veterinarians the majority of the samples (1282/1564) were also analysed for E. coli, Rota-, Coronavirus and Cryptosporidium spp. using the Bio-X Easy-Digest-ELISA (Bio-X Diagnostics S.P.R.L.) in order to increase the diagnostic spectrum of pathogens. This commercial ELISA kit was performed according to the manufacturer's instructions.

As all samples were processed within the scope of the routine diagnostic in our Quality management certified laboratory, they were initially only analysed by the methods, routinely used there. In order to obtain current data about the frequency of the different Giardia species in calves in Southern Germany most of the Giardiapositive samples of the present study were genotyped within the scope of another investigation along with further Giardia-positive samples of diarrhoeic and healthy calves [27]. Further investigations like quantifying the number of cysts and oocysts, respectively, differentiating Eimeria-oocysts and genotyping Cryptosporidium spp. by PCR were not performed because of logistic, personnel and financial reasons.

\section{Statistical analysis}

Statistical analysis was run using Microsoft-Excel-2010 software, PASW Statistics 18 (Predictive Analysis SoftWare - SPSS Inc.) and R [28]. 
The $t$-test for independent samples and an ANOVA (analysis of variance) were performed to investigate the differences in the mean age of the sampled animals in the single months.

For each disease (binary response: yes/no) a generalized additive logistic model was fitted using the statistical program $\mathrm{R}$ and the package mgcv $[29,30]$. The models try to explain the relative risk of infection depending on the age of the calves and the time of the year. Therefore the age of the calves is fitted by using thin plate regression splines with quantile-based knots and the time of the year by using cyclic penalized B-splines [31] and twelve equidistant knots for each month. Because of limited samples of calves $>80$ days these models were calculated just using the dates of calves $\leq 80$ days. For easier interpretation and visualization on the proportion-scale of infection the smooth curves were transformed. The obtained figures show the multiplicative effect of age respectively the season on the relative risk of infection for a given value of the other covariate.

For all analysis, a $\mathrm{P}$-value of $<0.01$ was considered to be significant.

\section{Results}

\section{Samples}

From January 1st - December 31st 2012 1564 faecal samples from calves (1-369 days old) were processed. The mean age of the sampled calves was 22.4 days (median $=11 \mathrm{~d}, \mathrm{n}=1423$ ). The result of the ANOVA shows, that there was a significant difference in the mean age of the sampled animals, sent in in the single months. Furthermore the boxplots, presenting the age composition in the single months, and the results of the $t$-test show in detail, in which months the calves were on average (significantly) younger or older compared with the remaining months (Figure 1).

\section{Results of the direct detection methods}

In $896 / 1564$ examined samples (57.3\%) at least one parasite was detectable by microscopical methods.

Giardia-cysts were detected in 112/1564 examined samples (7.2\%). The Giardia-positive calves were between 3 and 130 days old (mean $=46.5 \mathrm{~d}$, median $=42 \mathrm{~d}$, $\mathrm{n}=101$ ) with the highest rate of cyst excretion $(28.4 \%)$ in 61-90 days old animals (Figure 2). It is significant, that the age had a nonlinear influence on the probability of being infected with Giardia spp. and the odds of being infected with Giardia spp. increased slowly up to 8 times from about 12 days to 30 days (Figure 3 ). There was no seasonal influence on the odds of being infected with Giardia spp. (Figure 4). A mono-infection with Giardia spp. was diagnosed in 46 calves (2.9\%) whereas a mixed-infection was found in 15 samples (1.0\%) for Cryptosporidium spp. and in 51 samples (3.3\%) for Eimeria spp. (Table 1).

Cryptosporidium-oocysts were detected in 646/1564 examined samples (41.3\%). They had the size and morphology

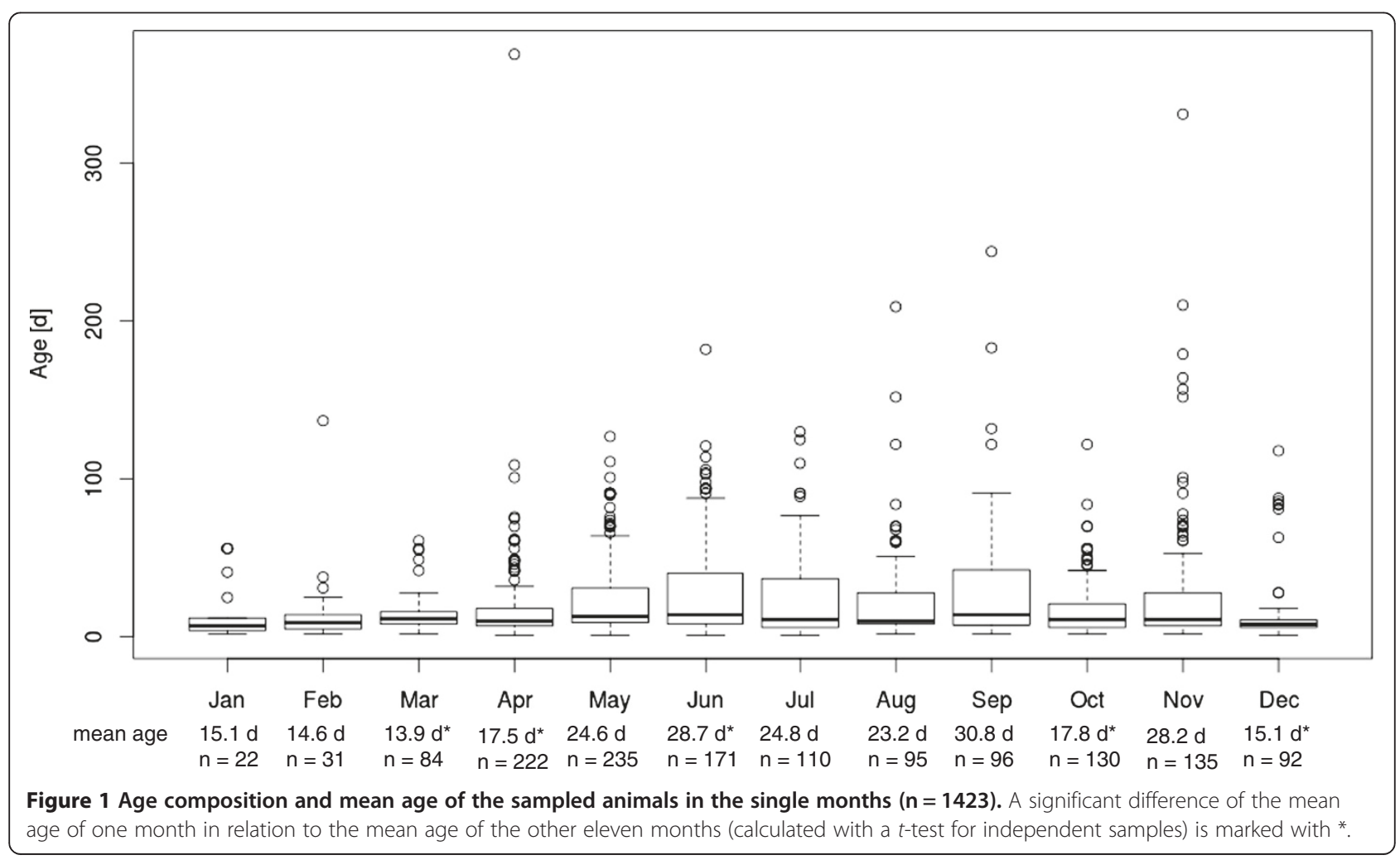




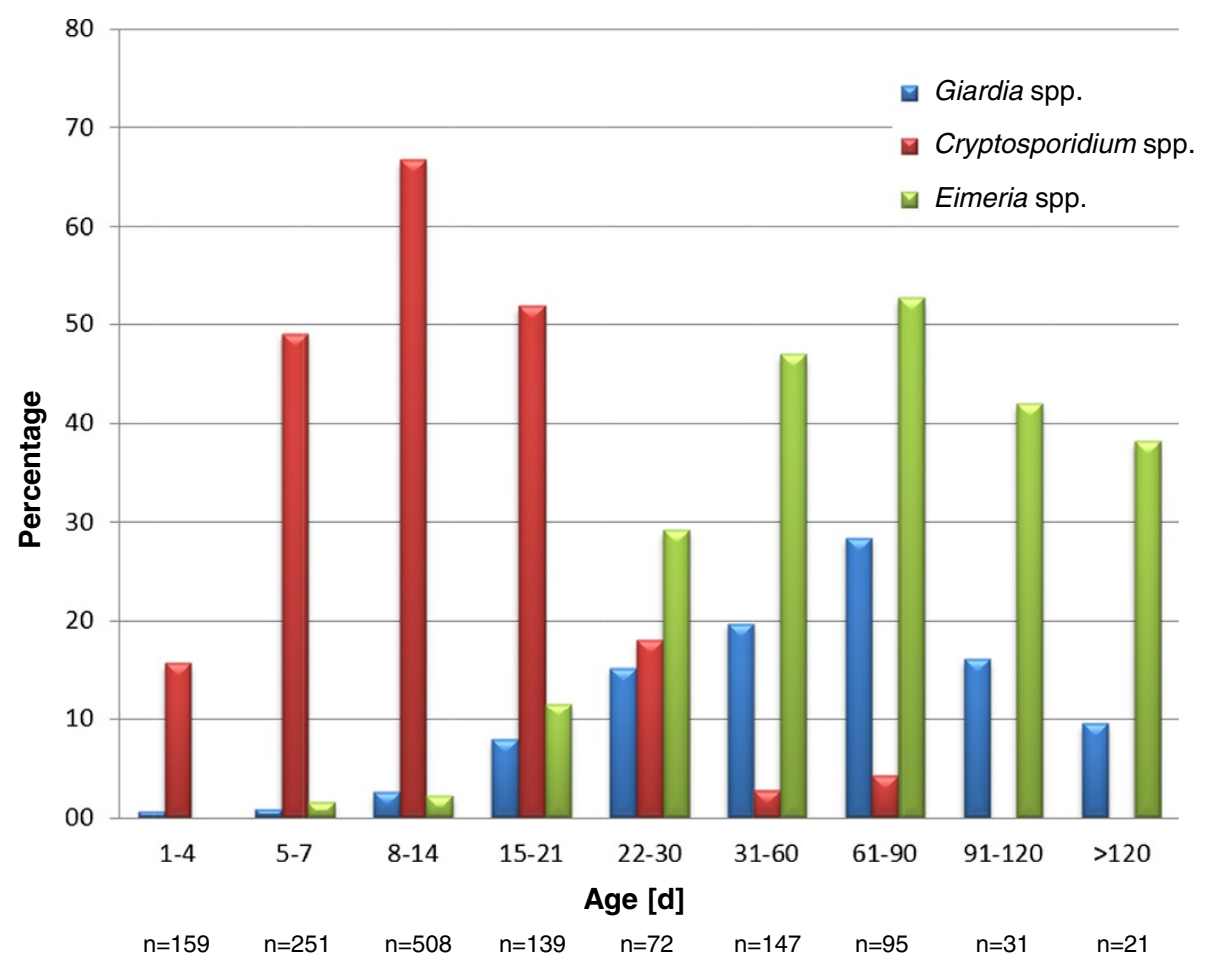

Figure 2 Age dependent frequencies of cyst/oocysts from Giardia spp., Cryptosporidium spp. and Eimeria spp. $(n=1423)$.

of C. parvum. The Cryptosporidium-positive calves were between 2 and 77 days old ( mean $=11.3 \mathrm{~d}$, median $=10$ $\mathrm{d}, \mathrm{n}=580$ ) with the highest rate of oocysts excretion $(66.7 \%)$ in $8-14$ days old calves (Figure 2). It is significant, that the age had a nonlinear influence on the probability of being infected with Cryptosporidium spp. and the odds of being infected with Cryptosporidium spp. increased up to 4.5 times until an age of 10 days. After that the odds decreased continuously and was approaching zero at about 30 days (Figure 3 ). There was no significant seasonal influence on the frequency of Cryptosporidium spp. (Figure 4).

Eimeria-oocysts were detected in 208/1564 examined samples (13.3\%). The Eimeria-positive calves were between 5 and 331 days old (mean $=55.0 \mathrm{~d}$, median $=49 \mathrm{~d}$, $\mathrm{n}=192)$ with the highest rate of oocysts excretion $(52.6 \%)$ in 61-90 days old calves (Figure 2). It is significant, that the age had a nonlinear influence on the probability of being infected with Eimeria spp. and the odds of being infected with Eimeria spp. increased continuously up to 30 times from about 20 days to 60 days (Figure 3). There was a significant seasonal influence on the frequency of Eimeria spp. (Figure 4): the odds of being infected with Eimeria spp. in March and April decreased by about half and increased up to 2.3 times between July and September.

The distribution of mono- and mixed-infections is presented in Table 1.

\section{Results of the ELISA}

E. coli was detected in $12(0.9 \%)$, Rotavirus in 485 (37.8\%), Coronavirus in 43 (3.4\%) and Cryptosporidium spp. in 581 (45.3\%) faecal samples of the part analysed using ELISA ( $\mathrm{n}=1282)$. The mean age of the positive tested calves was 24.8 days $(\mathrm{n}=12), 12.1$ days $(\mathrm{n}=443)$, 9.0 days $(\mathrm{n}=39)$ and 12.1 days $(\mathrm{n}=532)$, respectively. In $612 / 1282$ samples only one pathogen was found (47.7\%). Two and three pathogens were found in 250/1282 (19.5\%) and 3/1282 (0.2\%) calves respectively (Table 2).

In the 1282 samples, examined with the microscope and the ELISA, 522 were positive for Cryptosporidium spp. in both methods, 59 only in the ELISA and 29 only in the microscopical examination. Thus, of the 610/1282 samples positive for Cryptosporidium spp. in the ELISA or the microscopical examination, $95.3 \%$ (581/610) could be detected by the ELISA and $90.3 \%(551 / 610)$ by the microscopical examination.

\section{Discussion}

The study reveals that Cryptosporidium spp. and Rotavirus are the most prevalent pathogens in diarrhoeic calves up to one year old in Southern Germany, followed by Eimeria spp. and Giardia spp. Coronavirus and E. coli were diagnosed comparatively infrequently.

The detection rate of $7.2 \%$ of Giardia spp. is much lower compared to the obtained prevalences in many former studies; although prevalences of this pathogen in 

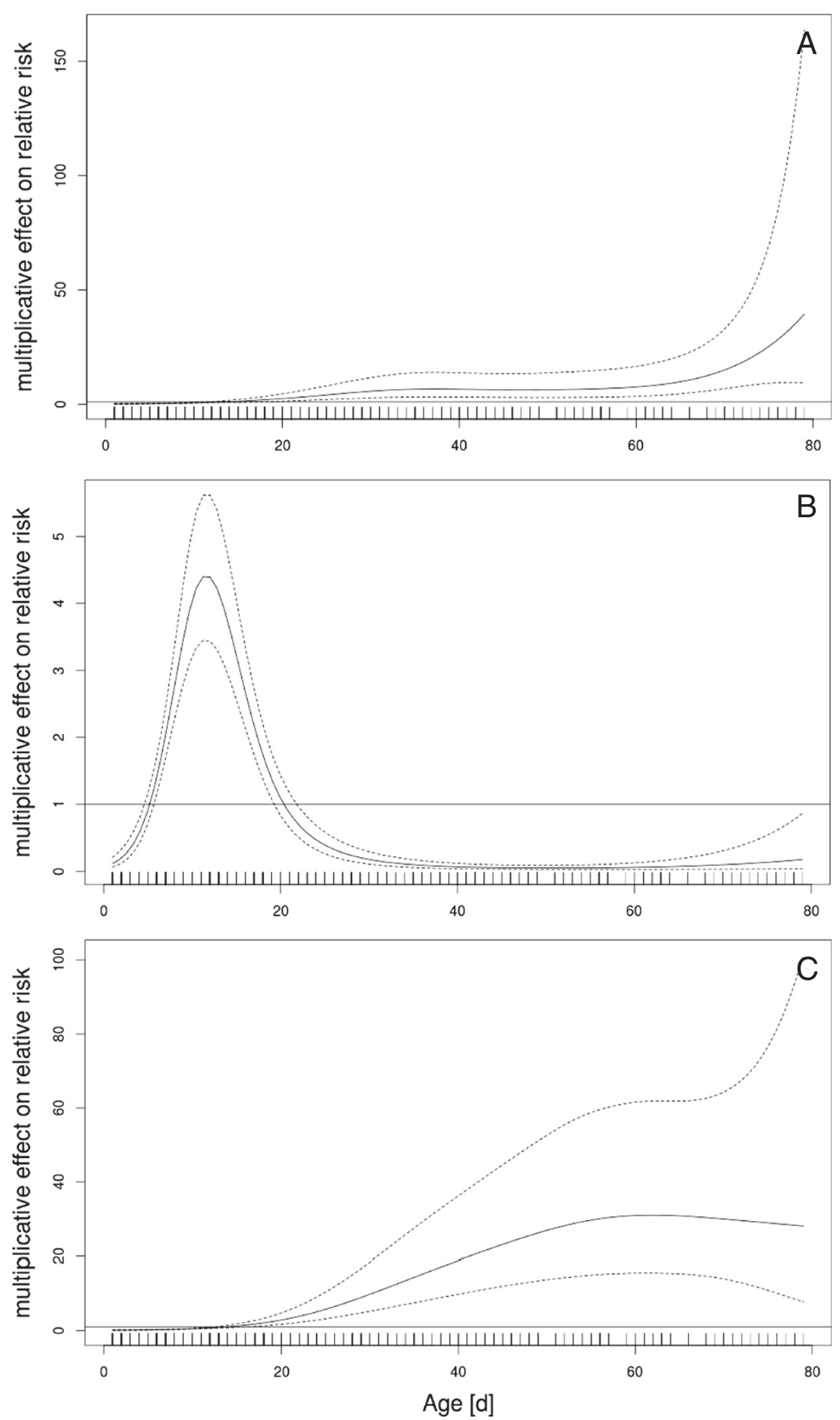

Figure 3 Odds of infection at different age $(\mathbf{n}=\mathbf{1 3 5 0})$. Straight line: level with no influence; ---: 99\% confidence interval. A: Giardia spp.; B: Cryptosporidium spp.; C: Eimeria spp. 

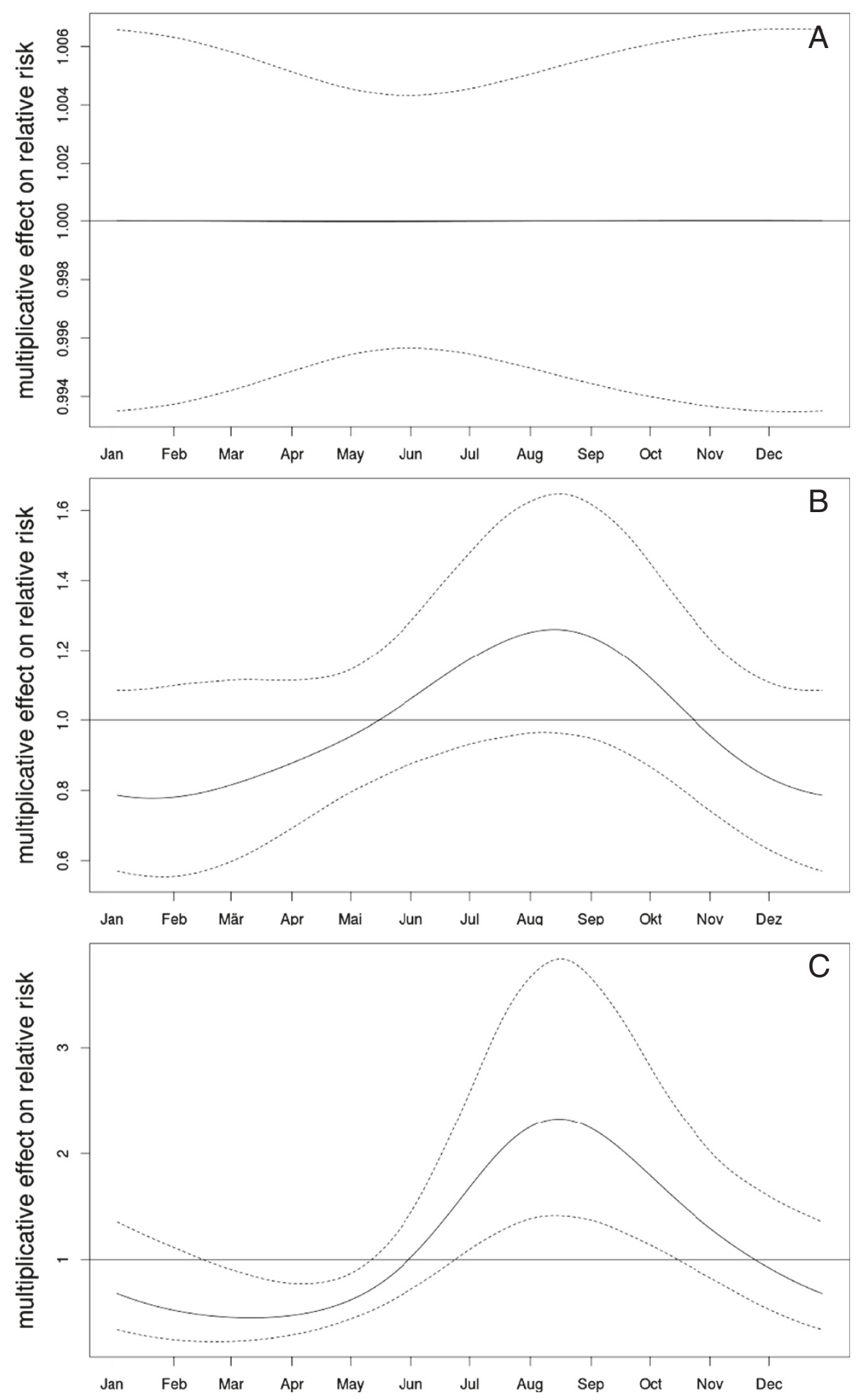

Figure 4 Odds of infection in the different months $(n=1350)$. Straight line: level with no influence; -: 99\% confidence interval. A: Giardia spp.; B: Cryptosporidium spp.; C: Eimeria spp.

general are differing markedly as shown previously $[1,20,32]$. In a recent European study using a commercially available monoclonal antibody-based ELISA, 51.2\% of 2-16 weeks old calves in the area of Berlin/Germany were infected with Giardia spp. [33]. In the present study the highest detection rate of Giardia spp. was in 
Table 1 Number and percentage of calves with a mono-/mixed-infection with Giardia spp., Cryptosporidium spp. and Eimeria spp.

\begin{tabular}{lcc}
\hline \multirow{2}{*}{ Parasite(s) detected } & \multicolumn{2}{c}{ Calves $(\mathbf{n}=\mathbf{1 5 6 4 )}$} \\
\cline { 2 - 3 } & Number & \% \\
\hline Giardia spp. only & 46 & 2.94 \\
Cryptosporidium spp. only & 627 & 40.09 \\
Eimeria spp. only & 153 & 9.78 \\
Giardia spp. + Eimeria spp. & 51 & 3.26 \\
Giardia spp. + Cryptosporidium spp. & 15 & 0.96 \\
Cryptosporidium spp. + Eimeria spp. & 4 & 0.26 \\
None & 668 & 42.71 \\
\hline
\end{tabular}

(Results of the microscopic examination).

calves between 61 and 90 days of age with $28.4 \%$. This is in line with other studies, which also revealed highest prevalence in about 3 months old calves [20,34]. By contrast other authors reported highest prevalence in 4-7 and 4 week old calves, respectively [35,36], whereas in Huetink et al. [37] it was highest in 4-5 month old animals. An impact of season on the probability of a giardiosis could not be shown. As discussed by Hamnes et al. [20], there are studies, showing seasonal variations in the prevalence of Giardia spp., and also other studies, not having found a seasonal impact on the prevalence. The role of giardiosis as a cause of diarrhoea in ruminants is still unclear $[8,13]$. In former studies Giardia spp. is thought to be the reason for diarrhoea and ill thrift in calves $[38,39]$ whereas in others no association between diarrhoea and Giardia-infection could be demonstrated [37,40,41]. Giardiosis in ruminants is often asymptomatic. It is unclear, when clinical symptoms

Table 2 Number and percentage of calves with a mono-/mixed-infection with E. coli, Rota-, Coronavirus and Cryptosporidium spp.

\begin{tabular}{lcc}
\hline \multirow{2}{*}{ Enteropathogen(s) detected } & \multicolumn{2}{c}{ Calves $(\mathbf{n}=\mathbf{1 2 8 2})$} \\
\cline { 2 - 3 } & Number & $\%$ \\
\hline E. coli only & 9 & 0.70 \\
Rotavirus only & 245 & 19.11 \\
Coronavirus only & 11 & 0.86 \\
Cryptosporidium spp. only & 347 & 27.07 \\
E. coli + Rotavirus & 1 & 0.08 \\
E. coli + Cryptosporidium spp. & 1 & 0.08 \\
Rotavirus + Coronavirus & 18 & 1.40 \\
Rotavirus + Cryptosporidium spp. & 218 & 17.00 \\
Coronavirus + Cryptosporidium spp. & 12 & 0.94 \\
E. coli + Rotavirus + Cryptosporidium spp. & 1 & 0.08 \\
Rotavirus + Coronavirus + Cryptosporidium spp. & 2 & 0.16 \\
None & 417 & 32.53 \\
\hline Results of ELISA-screning).
\end{tabular}

(Results of ELISA-screening). appear [8], as this is influenced by many factors like species/breed of host, species of Giardia, age, immune competence, frequency of infection, nutrition and concurrent infections [4]. However, also the role of an asymptomatic infection as a cause of production loss in calves is not yet appropriately investigated. Olson et al. [42] showed an association between a Giardia-infection and a reduced rate of weight gain, an impaired feed efficiency and a decreased carcass weight in experimentally infected lambs. On the contrary no significant difference in the average weight gain, the feed efficiency and the dry matter intake between Giardia spp. infected and non-infected steers could be found by Ralston et al. [43]. The present results indicate that Giardia spp., being the only pathogen found in some samples, may contribute to diarrhoea in older calves. In a former study, having examined 20 calves regularly from birth until 4 month of age, an association of giardiosis with diarrhoea was shown, since in a few cases no additional pathogen could be found at the time of a diarrhoea episode [38]. However, these calves had also been diagnosed Cryptosporidium-positive at some time during the study, with having found Cryptosporidium-oocysts on average earlier than Giardia-cysts. So it is possible that a former infection, in this case with Cryptosporidium spp., may favour the pathogenic potential of Giardia spp. Hence, further investigations are necessary with regard to Giardia spp. as cause of diarrhoea in calves and to production loss in asymptomatic calves [8]. In order to obtain current data about the frequency of the different Giardia species in calves in Southern Germany and to evaluate a speciesspecific pathogenicity, a further study was undertaken, including among others most of the Giardia-positive samples of the present study [27]: G. bovis has been identified in $91.8 \%$, G. duodenalis in $7.3 \%$ and a mixed template of G. duodenalis and G. bovis in $0.9 \%$ of the PCR-positive samples. This showed that although the livestock-specific species $G$. bovis has been diagnosed most frequently, the potential zoonotic species G. duodenalis is also present in calves in Southern Germany and thus might be a risk for animal handlers. Regarding a species-specific pathogenicity the results indicated that the livestockspecific species G. bovis might contribute to diarrhoea in calves, as it was the only pathogen found in a proportion of the samples from diarrhoeic calves, whereas G. duodenalis was only found in mixed infections with Cryptosporidium spp. or Eimeria spp.

The highest detection rate was found for Cryptosporidium spp. regardless of the examination method. Because of the low age of nearly all calves with a Cryptosporidium-infection in this study it is assumed, that almost all of them were infected with C. parvum, the species most often found in young calves, although $C$. bovis cannot be completely excluded. In previous studies in Germany the frequencies for 
C. parvum varied between $21.5 \%$ and $44.0 \%$ and were thus lower than in the present study $[44,45]$. As reviewed by Hamnes et al. [20] the prevalence of Cryptosporidium spp. in studies around the world varies from 6.2 to close to $100 \%$. The age related frequencies in the present study, with the highest detection rate $(66.7 \%)$ in calves between 8 and 14 days coincide with the results of former studies $[14,46]$. Not finding a seasonal influence on the risk of being infected with Cryptosporidium spp. is in line with the results of some former studies, whereas others have found such an influence [discussed by 20].

Eimeria-oocysts were detected in $13.3 \%$ of the samples. Compared with other studies in Germany and Austria with prevalences of $59.4 \%$ and $83.7 \%$, respectively, this frequency is quite low $[19,47]$. In these two studies $E$. bovis and E. zuernii were the most frequent species found. As the species-differentiation was not performed in this study, we can only assume, that the majority of the Eimeria-oocysts of the diarrhoeic animals here probably also belong to these two high pathogenic species $[17,19]$. In this study the age dependent frequency was highest in calves between 61-90 days of age. This is similar to the results of Lentze et al. [48], who found a significantly increasing risk of an Eimeria-infection until 3 months of age. In another investigation the highest prevalence was in animals between 3 and 12 months [49]. An association between season and frequency of Eimeria spp. was found in this study, with the highest odds of an Eimeriosis between July and September and the lowest between March and April. These results are similar to that of another study [21], whereas Daugschies and Najdrowski [17] indicated an increase in spring in pastured calves in their first grazing season.

Rotavirus is the second most common pathogen detected in this study and a mixed infection with Cryptosporidium spp. was found to be in about half of the Rotavirus-positive samples. Also in former studies these two pathogens were the infectious agents, most often found in diarrhoeic young calves [50-52]. Bartels et al. [53] found a high rate of mixed infections of Cryptosporidium and Rotavirus in his study on young Dutch dairy calves. The investigation of different risk factors showed that one risk factor for C. parvum was the presence of one or more calves of the same age shedding Rotavirus. In that study the prevalence of both parasites was highest in 2-week old calves. In the study of Uhde et al. [52] Rotavirus was the infectious agent that was most often found in diarrhoeic calves, either alone or in mixedinfections with mostly Cryptosporidium. As discussed there, much indicates that Rotavirus is a primary pathogen causing diarrhoea in neonatal calves. That is why Rotavirus is thought to have a predominant role in the pathogenesis of neonatal calf diarrhoea in that study [52]. Which pathogen of the two most frequent - Cryptosporidium spp. or
Rotavirus - has the predominant role in the present study remains unclear. In contrary to the high detection rates of Rotavirus and Cryptosporidium spp. low ones were found for E. coli and Coronavirus, what goes in line with the results of other European studies [51-53].

\section{Conclusions}

This study shows that, in addition to Eimeria spp., Giardia spp. seems to play a contributing role of notable importance in diarrhoea in older calves, whereas Cryptosporidium spp. and Rotavirus are mostly relevant in young calves in Southern Germany.

\section{Competing interests}

The authors declare that they have no competing interests.

\section{Authors' contributions}

JG carried out the examination by microscope and ELISA, analysed and interpreted the data and drafted the manuscript, DR performed the statistical analysis, KP and MS conceived of the study, participated in its design and conception and helped to draft the manuscript. All authors read and approved the final manuscript.

\section{Acknowledgements}

We thank the veterinarians, the Bayerische Tierseuchenkasse and our colleagues in the lab, especially Elisabeth Kiess, Kathrin Simon and Tim Tiedemann for their respective contributions to the study.

\section{Author details}

${ }^{1}$ Comparative Tropical Medicine and Parasitology, Faculty of Veterinary Medicine, Ludwig-Maximilians-Universität München, Leopoldstr. 5, D-80802 Munich, Germany. ${ }^{2}$ Statistical Consulting Unit, Department of Statistics, Ludwig-Maximilians-Universität München, Akademiestr. 1, D-80799 Munich, Germany.

Received: 1 November 2013 Accepted: 18 February 2014

Published: 26 February 2014

\section{References}

1. Geurden T, Vercruysse J, Claerebout E: Is Giardia a significant pathogen in production animals? Exp Parasitol 2010, 124:98-106.

2. Olson ME, O'Handley RM, Ralston BJ, McAllister TA, Thompson RC: Update on Cryptosporidium and Giardia infections in cattle. Trends Parasitol 2004, 20:185-191.

3. Monis PT, Caccio SM, Thompson RC: Variation in Giardia: towards a taxonomic revision of the genus. Trends Parasitol 2009, 25:93-100.

4. Thompson RC, Monis P: Giardia-from genome to proteome. In Advances in Parasitoogyl. Volume 78. Edited by Rollinson D, Hay SI. London: Elsevier; 2012:57-95.

5. Lalle M, Pozio E, Capelli G, Bruschi F, Crotti D, Caccio SM: Genetic heterogeneity at the beta-giardin locus among human and animal isolates of Giardia duodenalis and identification of potentially zoonotic subgenotypes. Int J Parasitol 2005, 35:207-213.

6. de Graaf DC, Vanopdenbosch E, Ortega-Mora LM, Abbassi H, Peeters JE: A review of the importance of cryptosporidiosis in farm animals. Int J Parasitol 1999, 29:1269-1287.

7. O'Donoghue PJ: Cryptosporidium and cryptosporidiosis in man and animals. Int J Parasitol 1995, 25:139-195.

8. Thompson RC, Palmer CS, O'Handley R: The public health and clinical significance of Giardia and Cryptosporidium in domestic animals. Vet $J$ 2008, 177:18-25.

9. Fall A, Thompson RC, Hobbs RP, Morgan-Ryan U: Morphology is not a reliable tool for delineating species within Cryptosporidium. J Parasitol 2003, 89:399-402.

10. Xiao L, Fayer R, Ryan U, Upton SJ: Cryptosporidium Taxonomy: recent advances and implications for public health. Clin Microbiol Rev 2004, 17:72-97. 
11. Stantic-Pavlinic M, Xiao L, Glaberman S, Lal AA, Orazen T, Rataj-Verglez A, Logar J, Berce I: Cryptosporidiosis associated with animal contacts. Wien Klin Wochenschr 2003, 115:125-127.

12. Fayer R, Santin M, Trout JM: Cryptosporidium ryanae n. sp. (Apicomplexa: Cryptosporidiidae) in cattle (Bos taurus). Vet Parasitol 2008, 156:191-198.

13. O'Handley RM, Olson ME: Giardiasis and cryptosporidiosis in ruminants. Vet Clin North Am Food Anim Pract 2006, 22:623-643.

14. Santin M, Trout JM, Xiao L, Zhou L, Greiner E, Fayer R: Prevalence and age-related variation of Cryptosporidium species and genotypes in dairy calves. Vet Parasitol 2004, 122:103-117.

15. Fayer R, Santin M, Xiao L: Cryptosporidium bovis n. sp. (Apicomplexa: Cryptosporidiidae) in cattle (Bos taurus). J Parasitol 2005, 91:624-629.

16. Lendner M, Etzold M, Daugschies A: Kryptosporidiose - ein Update. Berl Muench Tieraerztl Wochenschr 2011, 124:473-484.

17. Daugschies A, Najdrowski M: Eimeriosis in cattle: current understanding J Vet Med B Infect Dis Vet Public Health 2005, 52:417-427.

18. Eckert J, Friedhoff KT, Zahner H, Deplazes P: Lehrbuch der Parasitologie für die Tiermedizin. Stuttgart: Enke Verlag; 2008.

19. Bangoura B, Mundt HC, Schmäschke R, Westphal B, Daugschies A: Prevalence of Eimeria bovis and Eimeria zuernii in German cattle herds and factors influencing oocyst excretion. Parasitol Res 2012, 110:875-881.

20. Hamnes IS, Gjerde B, Robertson L: Prevalence of Giardia and Cryptosporidium in dairy calves in three areas of Norway. Vet Parasitol 2006, 140:204-216.

21. Stewart ID, Smith RP, Ellis-Iversen J: Eimeria species in cattle on farms in England and Wales. Vet Rec 2008, 162:482-483.

22. Tzipori S: The relative importance of enteric pathogens affecting neonates of domestic animals. Adv Vet Sci Comp Med 1985, 29:103-206.

23. Nussbaum DJ, Salord JR, Rimmele DD: Evaluation of quantitative latex agglutination for detection of Cryptosporidium parvum, E. coli K99, and rotavirus in calf feces. J Vet Diagn Invest 1999, 11:31431-31438.

24. Sturdee AP, Bodley-Tickell AT, Archer A, Chalmers RM: Long-term study of Cryptosporidium prevalence on a lowland farm in the United Kingdom. Vet Parasitol 2003, 116:97-113.

25. Heine J: Eine einfache Nachweismethode für Kryptosporidien im Kot. Zentralb/ Veterinaermed Reihe B 1982, 29:324-327.

26. Thornton SA, West AH, DuPont HL, Pickering LK: Comparison of methods for identification of Giardia lamblia. Am J Clin Pathol 1983, 80:858-860.

27. Gillhuber J, Pallant L, Ash A, Thompson RC, Pfister K, Scheuerle MC: Molecular identification of zoonotic and livestock-specific Giardia-species in faecal samples of calves in Southern Germany. Parasit Vectors 2013, 6:346.

28. R Core Team: $R$ : a language and environment for statistical computing. 2013. http://www.R-project.org/.

29. Wood SN: Generalized Additive Models: an introduction with R. Boca Raton: Chapman and Hall/CRC; 2006.

30. Wood SN: Fast stable restricted maximum likelihood and marginal likelihood estimation of semiparametric generalized linear models. J Roy Statist Soc Ser B 2011, 73:3-36.

31. Eilers PHC, Marx BD: Flexible Smoothing with B-splines and Penalties. Stat Sci 1996, 11:89-121.

32. Xiao L: Giardia infection in farm animals. Parasitol Today 1994, 10:436-438.

33. Geurden $T$, Vanderstichel R, Pohle H, Ehsan A, von Samson-Himmelstjerna G, Morgan ER, Camuset P, Capelli G, Vercruysse J, Claerebout E: A multicentre prevalence study in Europe on Giardia duodenalis in calves, with molecular identification and risk factor analysis. Vet Parasitol 2012, 190:383-390.

34. Trout JM, Santin M, Greiner E, Fayer R: Prevalence and genotypes of Giardia duodenalis in post-weaned dairy calves. Vet Parasitol 2005, 130:177-183.

35. Becher KA, Robertson ID, Fraser DM, Palmer DG, Thompson RC: Molecular epidemiology of Giardia and Cryptosporidium infections in dairy calves originating from three sources in Western Australia. Vet Parasitol 2004, 123:1-9.

36. Jäger M, Gauly M, Bauer C, Failing K, Erhardt G, Zahner H: Endoparasites in calves of beef cattle herds: management systems dependent and genetic influences. Vet Parasitol 2005, 131:173-191.

37. Huetink RE, van der Giessen JW, Noordhuizen JP, Ploeger HW: Epidemiology of Cryptosporidium spp. and Giardia duodenalis on a dairy farm. Vet Parasitol 2001, 102:53-67.

38. O'Handley RM, Cockwill C, McAllister TA, Jelinski M, Morck DW, Olson ME: Duration of naturally acquired giardiosis and cryptosporidiosis in dairy calves and their association with diarrhea. J Am Vet Med Assoc 1999, 214:391-396.

39. Xiao L, Herd RP, Rings DM: Concurrent infections of Giardia and Cryptosporidium on two Ohio farms with calf diarrhea. Vet Parasitol 1993, 51:41-48.

40. Bjorkman C, Svensson C, Christensson B, de Verdier K: Cryptosporidium parvum and Giardia intestinalis in calf diarrhoea in Sweden. Acta Vet Scand 2003, 44:145-152.

41. Quilez J, Sanchez-Acedo C, del Cacho E, Clavel A, Causape AC: Prevalence of Cryptosporidium and Giardia infections in cattle in Aragon (northeastern Spain). Vet Parasitol 1996, 66:139-146.

42. Olson ME, McAllister TA, Deselliers L, Morck DW, Cheng KJ, Buret AG, Ceri H: Effects of giardiasis on production in a domestic ruminant (lamb) model. Am J Vet Res 1995, 56:1470-1474.

43. Ralston BJ, Cockwill CL, Guselle NJ, Van Herk FH, McAllister TA, Olson ME: Prevalence of Giardia and Cryptosporidium andersoni and their effects on performance in feedlot beef cattle. Can J Anim Sci 2003, 83:153-159.

44. Joachim A, Krull T, Schwarzkopf J, Daugschies A: Prevalence and control of bovine cryptosporidiosis in German dairy herds. Vet Parasitol 2003 112:277-288.

45. Fiedler $\mathrm{vH}-\mathrm{H}$ : Zur Verbreitung von Kryptosporidien unter norddeutschen Rinderbeständen. Tierärztl Umschau 1985, 40:526-528.

46. Xiao L, Herd RP: Infection pattern of Cryptosporidium and Giardia in calves. Vet Parasitol 1994, 55:257-262.

47. Koutny H, Joachim A, Tichy A, Baumgartner W: Bovine Eimeria species in Austria. Parasitol Res 2012, 110:1893-1901.

48. Lentze T, Hofer D, Gottstein B, Gaillard C, Busato A: Häufigkeiten und Bedeutung von Endoparasiten bei Kälbern aus Schweizer Mutterkuhbetrieben. Dtsch Tierärztl Wschr 1999, 106:275-281.

49. Lassen B, Viltrop A, Raaperi K, Jarvis T: Eimeria and Cryptosporidium in Estonian dairy farms in regard to age, species, and diarrhoea. Vet Parasitol 2009, 166:212-219.

50. Snodgrass DR, Terzolo HR, Sherwood D, Campbell I, Menzies JD, Synge BA: Aetiology of diarrhoea in young calves. Vet Rec 1986, 119:31-34

51. de la Fuente R, Garcia A, Ruiz-Santa-Quiteria JA, Luzon M, Cid D, Garcia S, Orden JA, Gomez-Bautista M: Proportional morbidity rates of enteropathogens among diarrheic dairy calves in central Spain. Prev Vet Med 1998, 36:145-152.

52. Uhde FL, Kaufmann T, Sager H, Albini S, Zanoni R, Schelling E, Meylan M: Prevalence of four enteropathogens in the faeces of young diarrhoeic dairy calves in Switzerland. Vet Rec 2008, 163:362-366.

53. Bartels CJ, Holzhauer M, Jorritsma R, Swart WA, Lam TJ: Prevalence, prediction and risk factors of enteropathogens in normal and non-normal faeces of young Dutch dairy calves. Prev Vet Med 2010, 93:162-169.

doi:10.1186/1756-0500-7-112

Cite this article as: Gillhuber et al: Giardiosis and other enteropathogenic infections: a study on diarrhoeic calves in Southern Germany. BMC Research Notes 2014 7:112.

\section{Submit your next manuscript to BioMed Central and take full advantage of:}

- Convenient online submission

- Thorough peer review

- No space constraints or color figure charges

- Immediate publication on acceptance

- Inclusion in PubMed, CAS, Scopus and Google Scholar

- Research which is freely available for redistribution 